\title{
Comparison between sublingual 600 and 800 microgram misoprostol after mifepristone for MTP up to 9 weeks gestation
}

\author{
Srishti Thakur*, Charu Pratap
}

Department of Obstetrics and Gynecology, Subharti Medical College, Dehradun, Uttarakhand, India

Received: 26 September 2018

Accepted: 22 October 2018

*Correspondence:

Dr. Srishti Thakur,

E-mail: thakur.srishti@gmail.com

Copyright: (C) the author(s), publisher and licensee Medip Academy. This is an open-access article distributed under the terms of the Creative Commons Attribution Non-Commercial License, which permits unrestricted non-commercial use, distribution, and reproduction in any medium, provided the original work is properly cited.

\begin{abstract}
Background: The objective of the present study was to compare the efficacy between sublingual 600 and 800 microgram Misoprostol after administration of Mifepristone up to 9 weeks gestation, to compare the incidence of side effects between the two doses. To compare the acceptability between the two doses.

Methods: This study is a single-center, randomized study. The study is conducted at Fortis Escorts Hospital and Research Centre, Faridabad, during period of May 2014 to June 2015. 160 Pregnant women with singleton pregnancy up to 9 weeks gestation, visiting OPD of Obstetrics and Gynaecology, who wanted MTP by drug, after taking care of inclusion and exclusion criteria. An informed consent was taken from all the women.

Results: In terms of efficacy, both the groups were comparable (p value 0.509). Blood loss was comparable in both the groups ( $p$ value 0.147 ). In terms of side effects, itching and rashes ( $p$ value 0.004 ) and abdominal cramps ( $p$ value 0.001 ) was found to be more in women taking 800ug Misoprostol. Also, need for analgesia ( $\mathrm{p}$ value 0.001 ) was found to be more in women taking 800 ug Misoprostol.

Conclusions: Sublingual Misoprostol is comfortable and easier administration when compared to other routes and it has potential to be developed as a self-administered regimen. 600ug Sublingual Misoprostol is as efficacious as $800 \mathrm{ug}$ sublingual Misoprostol with significantly lesser side effects up to 7 weeks of gestation.
\end{abstract}

Keywords: Mifepristone, Misoprostol, Sublingual

\section{INTRODUCTION}

Unwanted pregnancy is a major public health problem with potentially serious consequences and therefore, inspite of various contraceptive methods available, need for abortion continues. ${ }^{1}$ In our country current ratio of abortion is 452 per 1000 live birth and more than $50 \%$ of these are unsafe. Medical abortion is a nonsurgical method for induction of abortion which is has become an alternative safe and effective method for first trimester pregnancy termination. Antiprogesterone such as Mifepristone (RU486) and prostaglandins like Misoprostol have been approved by FOGSI, for termination of pregnancy. These medical methods are an alternative to surgical abortions, requiring less training skills and expertise to perform, less risk of surgery and anaesthesia, need of operating room and is more natural. It permits greater privacy and is well tolerated physically and emotionally.

\section{Review of literature}

\section{Mifepristone (RU486)}

Mifepristone is a norethindrone derivative, synthetic potent antiprogesterone which acts by binding to progesterone receptor, thus blocking the effects of progesterone at the uterine level and provoking uterine contractions. ${ }^{2}$ The rate of complete abortion with RU486 is up to $95-100 \%$ by combining with a low dose 
prostaglandin making it a non-invasive alternative for early pregnancy termination. ${ }^{3}$ Prostaglandin stimulation by Mifepristone is by means of increase in the synthesis as well as direct effect on prostaglandin dehydrogenase, the main enzyme for the metabolism and deactivation of prostaglandins. ${ }^{4}$ Prostaglandins cause a profound constriction of the spiral arterioles, leading to ischemia and this decidual necrosis with bleeding and detachment of the embryo. ${ }^{5}$ After about 9 weeks, Mifepristone loses much of its effectiveness, because placenta takes over the manufacture of progesterone from the corpus luteum, thus decreasing the efficacy of its abortifacient effect. ${ }^{6,7}$

\section{Misoprostol}

Misoprostol (synthetic methyl analogue of PGE1) is cheap, does not require refrigeration and is associated with few gastrointestinal side effects. Misoprostol alone has lower abortifacient effect especially in early pregnancy. Higher doses are required if used alone, thus leading to higher incidence of side effects. The outcomes sought after various randomised controlled trials included mortality, failure to achieve complete abortion, need for surgical evacuation, ongoing pregnancy at follow-up, time of abortion (>3-6 hours), blood transfusion, blood loss (measured by drop in haemoglobin level), days of bleeding, pain abdomen and need for analgesia, nausea, vomiting and diarrhoea. Misoprostol acts by binding to myometrial cells to cause strong myometrial contractions leading to expulsion of fetus. According to RCOG (2004) guidelines, following regimen appears to be optimal for early medical abortion up to 9 weeks (63 days) of gestation.

Mifepristone $200 \mathrm{mg}$ orally followed 1-3 days later by Misoprostol 800 micrograms vaginally. For women at 4963 days of gestation, if abortion has not occurred 4 hours after administration of Misoprostol, a second dose of Misoprostol 400 microgram may be administered vaginally or orally.

According to FOGSI guidelines (2011), following regimen is followed from 49 to 63 days

- Day1-200mg Mifepristone tablet orally

- Day2- 800ug Misoprostol given orally or vaginally

- Day14- follow up visit to assess for completion of abortion

\section{Pharmacokinetics}

\section{Misoprostol}

Misoprostol is mainly a uterotonic agent (half-life of approximately 30 minutes) which can be given orally, vaginally, rectally and sublingually. Uterotonicity occurs with all routes of administration. Sublingual misoprostol has fast onset of action, high peak concentration and has a high bioavailability, convenient to administer and avoids the uncomfortable painful vaginal administration.
Sublingual misoprostol avoids first pass effect through the liver and therefore, may result in a higher complete abortion rate $(94 \%$ complete abortion rate) similar to vaginal administration though side effects were found to be slightly higher with sublingual misoprostol. ${ }^{8}$ According to Dahiya et al sublingual Misoprostol is as effective as oral Misoprostol 48 hours after administration of $200 \mathrm{mg}$ Mifepristone. ${ }^{9}$ According to Sahu RR et al following oral administration, the plasma concentration increased rapidly with a peak of $30 \mathrm{~min}$, declined rapidly by $120 \mathrm{~min}$, and remained low thereafter. ${ }^{10}$ In contrast, after vaginal administration, the plasma concentration gradually increased, reaching maximum levels after 70-80 min and slowly declined with detectable levels present after 6 hour. Vaginal Misoprostol was present in the circulation longer than oral Misoprostol and hence its duration of stimulation of the uterus exceeds that of oral Misoprostol. Mundle Shuchita (who used 400ug sublingual Misoprostol after 48 hours oral $200 \mathrm{mg}$ Mifepristone) also concluded that Sublingual Misoprostol was a safe, efficacious method. ${ }^{11}$ Similar result was found to be present in study by Shetty Jyothi, MNV Pallavi. ${ }^{12}$ Nusrat Shah et al who compared sublingual versus vaginal misoprostol in the management of missed miscarriage, concluded that sublingual misoprostol is as effective as vaginal misoprostol for medical management of missed miscarriage but is associated with an increased risk of side effects especially an unpleasant taste. ${ }^{13}$

Table 1: Comparison between different routes of misoprostol.

\begin{tabular}{|llll|}
\hline Route & $\begin{array}{l}\text { Onset of } \\
\text { action }\end{array}$ & $\begin{array}{l}\text { Duration } \\
\text { of action }\end{array}$ & Peak level \\
\hline Oral & 8 minutes & 2hours & 30 minutes \\
\hline Vaginal & 11 minutes & 3hours & $70-80$ minutes \\
\hline Sublingual & 20 minutes & 4hours & 30 minutes \\
\hline
\end{tabular}

\section{Dose and adverse effects of misoprostol}

The recommended dose of misoprostol is 400-800 microgram/day. ${ }^{14}$ Adverse effects of misoprostol are dose dependent, like nausea, vomiting, diarrhoea, abdominal pain, chills and rigors and fever, Mobius syndrome (congenital facial paralysis and limb defects) which occurs in infants of women who have taken misoprostol during first trimester in an unsuccessful attempt to induce abortion. Misoprostol is excreted into breast milk, levels become undetected within 5 hours of maternal ingestion. Breastfeeding women should be advised that misoprostol may cause infant diarrhoea. No significant drug interactions have been reported.

\section{Mifepristone ( $R U$ 486)}

Mifepristone has long half-life of 26-48 hours. After oral single dose, levels peaks around 1 hour. Serum levels plateau at $2.5 \mathrm{umol} / \mathrm{L}$ for $24-48$ hours and can still be 
measured for 5-7 days and therefore used as a single oral dose.

\section{Purpose of study}

According to various studies stated above, the efficacy of $800 \mathrm{ug}$ sublingual Misoprostol is higher than vaginal or oral route, although the side effects of sublingual route is slightly higher than the other routes. In this study, the dose of 800 ug was compared to 600 ug sublingual Misoprostol, and the side effects were observed in both the groups.

As side effects of Misoprostol is dose dependent, we observed whether the side effect of sublingual Misoprostol is reduced by lowering the dose of Misoprostol. Also, the efficacy of 800 ug sublingual Misoprostol was compared to 600ug sublingual Misoprostol, whether by lowering the dose of Misoprostol affected the efficacy by sublingual route. Studies that have been done for vaginal Misoprostol, was extrapolated to sublingual Misoprostol in this study.

The objective of the present study to compare the efficacy between sublingual 600 and 800 microgram Misoprostol after administration of Mifepristone up to 9 weeks gestation, to compare the incidence of side effects between the two doses, to compare the acceptability between the two doses.

\section{METHODS}

Study design: This study is a single-centre, randomized study. Setting: The study is conducted at Fortis Escorts Hospital and Research Centre, Faridabad Haryana, during period of May 2014 to June 2015. Subjects: Pregnant women with singleton pregnancy, who wanted MTP by drug, after taking care of inclusion and exclusion criteria.

This study was carried out in 160 pregnant women opting for MTP up to 9weeks gestation by medical method, visiting OPD of Obstetrics and Gynaecology and divided into two groups. An informed consent was taken from all the women.

\section{Group A}

Visit 1-A single dose of Mifepristone 200mg given orally.

Visit 2-A dose of Misoprostol 600ug was given sublingually after 48 hours interval of her first visit.

\section{Group B}

Visit1-A single dose of Mifepristone 200mg given orally

Visit2-A dose of Misoprostol 800ug was given sublingually after 48 hours interval of her first visit.

\section{Inclusion criteria}

- $\quad$ Age more than 18 years.

- Gestation less than or equal to 9 weeks pregnancy.

- The woman ready to return to OPD for follow ups as and when necessary.

- Pregnant woman requesting for early termination of pregnancy by taking medicines as per guidelines of the MTP act.

- Woman who understood that once she takes Mifepristone, she has to undergo termination and cannot change her mind and continue the pregnancy as Mifepristone could be teratogenic.

- Woman who were willing to undergo surgical procedure, in case the medical method fails or results in incomplete abortion.

- Woman who had access to telephone call and emergency medical treatment in case of excessive bleeding or pain etc.

\section{Exclusion criteria}

- Intrauterine pregnancy over 9 weeks

- Confirmed or suspected ectopic pregnancy

- Known allergy to Mifepristone or Prostaglandin analogue or known hypersensitivity

- Concurrent long-term use of corticosteroids therapy

- Patient on anticoagulants

- Known haemorrhagic disorder

- Chronic renal insufficiency

- Severe anaemia (haemoglobin less than 9)

- Smokers $>35$ years of age (risk of thromboembolism is more)

- Undiagnosed adenexal mass

- IUCD in situ

- Chronic adrenal insufficiency

- More than or equal to three previous caesarean section

- Inherited porphyrias

- Epilepsy

- Acute liver disease

- Lack of access to emergency care.

\section{Statistical analysis}

The data was analyzed by using Chi Square test for categorical variables, while for continuous variables, the statistical $\mathrm{T}$ test/Non-parametric Wilcoxon Mann Whitney test was used for comparing different parameters between sublingual 600 and 800 microgram misoprostol groups. The $\mathrm{p}$ value $<0.05$ was taken as level of statistical significance.

Demographic details like age, parity, address, period of amenorrhea, menstrual history, detailed present and past Obstetrical history (including previous abortions and caesarean deliveries), relevant past medical and surgical history was taken. General physical, systemic, abdominal and local examination was carried out. 
The cases were enrolled in the study after informed consent after explaining to them the nature of study as well as possible risks and benefits and the visiting schedule. Investigation like hemogram, blood group, ultrasound (to confirm intrauterine pregnancy and period of gestation) was done on day 1. Anti-D immunoglobulin was given immediately after administration of Mifepristone if the woman was found to be Rh negative.

The opaque sealed envelopes were stored in the OPD (Outpatient department). Randomization of the women to one of the 2 treatment arms was done. Each Pregnant woman picked up an envelope which contained a folded card. Those marked with " $A$ " indicated randomization to receive $600 \mathrm{ug}$ sublingual misoprostol and those marked "B" would receive 800 ug sublingual misoprostol.

Patients were given a dose of antiemetic and antispasmodic one hour prior to giving misoprostol to both the groups. Patients were asked to come on day 14 with haemoglobin (to look for drop in haemoglobin) and ultrasound (to check for completion of abortion). Presence of gestational sac or products of conception 2 weeks after the dose of Mifepristone was considered as a failure and suction evacuation was to be done.

\section{Follow Up}

- Pelvis ultrasound after 14 days (to check the completion of abortion).
- Amount of bleeding (assessed by drop in haemoglobin level).

- $\quad$ Need for analgesia

- Presence of GI symptoms (nausea and vomiting requiring antiemetics)

- Need for blood transfusion

- Need for any additional oxytocics

- Need for suction evacuation will be assessed

\section{Primary outcomes}

- Completeness of abortion

- Severity of side effects

- Amount of bleeding

\section{Secondary outcomes}

- Need for analgesia

- Need for additional doses of Misoprostol or other Oxytocics

- Induction abortion interval

\section{RESULTS}

$600 \mu \mathrm{g}$ and $800 \mu \mathrm{g}$ sublingual Misoprostol have comparable efficacy in terms of complete abortion rate $(90 \%$ vs $95 \%$, p value $=0.369)$, failure rate being statistically similar $(10 \%$ vs $5 \%$, p value $=0.369)($ Table $2,3)$.

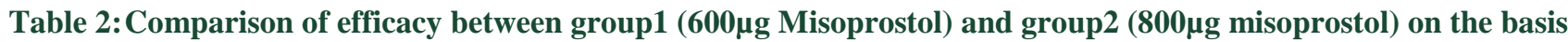
of complete abortion.

\begin{tabular}{|c|c|c|c|c|}
\hline & \multicolumn{2}{|l|}{ Group } & \multirow{2}{*}{ Total } & \multirow{2}{*}{ P value } \\
\hline & Group 1 & Group 2 & & \\
\hline Number of women with complete abortion & $72(90.00 \%)$ & $76(95.00 \%)$ & $148(92.50 \%)$ & \multirow{2}{*}{0.369} \\
\hline Total & $80(100.00 \%)$ & $80(100.00 \%)$ & $160(100.00 \%)$ & \\
\hline
\end{tabular}

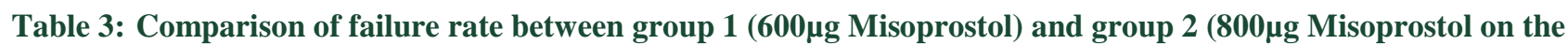
basis of incomplete abortion.

\begin{tabular}{|c|c|c|c|c|}
\hline & \multicolumn{2}{|l|}{ Group } & \multirow{2}{*}{ Total } & \multirow{2}{*}{ P value } \\
\hline & Group 1 & Group 2 & & \\
\hline Incomplete abortion & $8(10.00 \%)$ & $4(5.00 \%)$ & $12(7.50 \%)$ & \multirow{2}{*}{0.369} \\
\hline Total & $80(100.00 \%)$ & $80(100.00 \%)$ & $160(100.00 \%)$ & \\
\hline
\end{tabular}

$600 \mu \mathrm{g}$ sublingual Misoprostol was found to be as efficacious as $800 \mu \mathrm{g}$ sublingual Misoprostol from 4 to 7 weeks period of gestation (complete abortion rate $91.67 \%$ in group 1 and $97.71 \%$ in group2, $\mathrm{P}$ value was 0.32 ).

However, beyond 7 weeks Period of gestation, complete abortion rate was $74.07 \%$ in group 1 and $94.44 \%$ in group 2 ( $\mathrm{p}$ value $=0.031)$, which is statistically significant which means sublingual Misoprostol in the dose of $600 \mu \mathrm{g}$ is not as effective as $800 \mu \mathrm{g}$ for termination of pregnancy above 7 weeks Pregnancy (Table 4). Shivering and fever was present in 10 out 80 women ( $12.5 \%$ women) belonging to group 1 and 39 out of 80 women (48.75\% women) belonging to group 2 . $\mathrm{P}$ value was found to be less than 0.0005 which is statistically highly significant meaning shivering and fever was significantly less in women who took $600 \mu \mathrm{g}$ sublingual Misoprostol as compared to women taking $800 \mu \mathrm{g}$ sublingual Misoprostol. Itching and 
rashes were present in 4 out 80 women (5\% women) belonging to group 1 and 17 out of 80 women $(21.25 \%$ women) belonging to group 2 . $\mathrm{P}$ value was found out to be 0.004 which is statistically significant meaning that itching and rashes were significantly more in women taking $800 \mu \mathrm{g}$ Sublingual Misoprostol as compared to women taking $600 \mu \mathrm{g}$ Sublingual Misoprostol. None of the women taking $600 \mu \mathrm{g}$ sublingual Misoprostol had diarrhoea (group1) whereas 2 out of 80 women $(2.5 \%$ women) belonging to group 2 suffered from diarrhoea. $\mathrm{P}$ value was 0.49 meaning thereby that the difference in the occurrence of diarrhoea was not statistically different in the two groups.
In terms of Haemoglobin drop in percentage, (as shown in Figure 5), it was $0.37 \%$ in group 1 (sublingual $600 \mu \mathrm{g}$ Misoprostol) and $0.2 \%$ in group 2 (sublingual $800 \mu \mathrm{g}$ Misoprostol). $\mathrm{P}$ value was 0.147 which means haemoglobin drop in both the groups was statistically similar. Need of additional Oxytocics was in 8 women out of 80 (10\% women) belonging to group 1 and 3 out of 80 (3.75\% women) belonging to group 2 .

$\mathrm{P}$ value was 0.210 meaning that although more women in group1 needed additional Oxytocics as compared to group 2, the difference was not statistically significant.

Table 4: Comparison of efficacy between group 1 and group 2 period of gestation wise.

\begin{tabular}{|c|c|c|c|c|c|}
\hline \multirow{2}{*}{\multicolumn{3}{|c|}{ POG (weeks) }} & \multicolumn{2}{|l|}{ Efficacy } & \multirow{2}{*}{ P value } \\
\hline & & & Complete & incomplete & \\
\hline \multirow{3}{*}{4} & \multirow{2}{*}{ Group } & 600 miso & $11(91.67 \%)$ & $1(8.33 \%)$ & \multirow{3}{*}{1} \\
\hline & & 800 miso & $12(92.31 \%)$ & $1(7.69 \%)$ & \\
\hline & Total & & $23(92.00 \%)$ & $2(8.00 \%)$ & \\
\hline \multirow{3}{*}{5} & \multirow{2}{*}{ Group } & 600 miso & $3(75.00 \%)$ & $1(25.00 \%)$ & \multirow{3}{*}{1.0} \\
\hline & & 800 miso & $1(100.00 \%)$ & $0(0.00 \%)$ & \\
\hline & Total & & $4(80.00 \%)$ & $1(20.00 \%)$ & \\
\hline \multirow{3}{*}{6} & \multirow{2}{*}{ Group } & 600 miso & $25(92.59 \%)$ & $2(7.41 \%)$ & \multirow{3}{*}{1} \\
\hline & & 800 miso & $26(96.30 \%)$ & $1(3.70 \%)$ & \\
\hline & Total & & $51(94.44 \%)$ & $3(5.56 \%)$ & \\
\hline \multirow{3}{*}{7} & \multirow{2}{*}{ Group } & 600 miso & $9(90.00 \%)$ & $1(10.00 \%)$ & \multirow{3}{*}{1} \\
\hline & & 800 miso & $3(100.00 \%)$ & $0(0.00 \%)$ & \\
\hline & Total & & $12(92.31 \%)$ & $1(7.69 \%)$ & \\
\hline \multirow{3}{*}{8} & \multirow{2}{*}{ Group } & 600 miso & $20(74.07 \%)$ & $7(25.93 \%)$ & \multirow{3}{*}{0.031} \\
\hline & & 800 miso & $34(94.44 \%)$ & $2(5.56 \%)$ & \\
\hline & Total & & $54(85.71 \%)$ & $9(14.26 \%)$ & \\
\hline \multirow{3}{*}{ Total } & \multirow{2}{*}{ Group } & 600 miso & $72(90.00 \%)$ & $8(10.00 \%)$ & \multirow{3}{*}{0.369} \\
\hline & & 800 miso & $76(95.00 \%)$ & $4(5.00 \%)$ & \\
\hline & Total & & $148(92.50 \%)$ & $12(7.50 \%)$ & \\
\hline
\end{tabular}

\section{DISCUSSION}

Complete abortion rate was statistically similar in both the groups. 72 Out of 80 women in group 1 (90\%) whereas 76 out of 80 women in group $2(95 \%)$ had complete abortion. $\mathrm{P}$ value was 0.3 which means the difference in efficacy in terms of complete abortion amongst the two groups is not statistically significant, meaning thereby that both the doses are equally effective (Table 2). 8 (10\%) women out of 80 in group 1 whereas 4 $(5 \%)$ women out 80 in group 2 had incomplete abortion. Comparing the $\mathrm{P}$ value in both the groups, the difference in efficacy in terms of incomplete abortion was not statistically significant, thereby emphasizing that both the dosage regimens are equally effective (Table 3 ).

As depicted in Table 4 at Period of gestation 4 weeks, $91.67 \%$ of women in group 1 whereas $92.31 \%$ women in group 2 had complete abortion ( $\mathrm{P}$ value=1). At period of gestation 5 weeks, $75 \%$ of women in group 1 whereas $100 \%$ women in group 2 had complete abortion (P value $=1$ ). At period of gestation 6 weeks, $92.59 \%$ of women in group 1 whereas $96.3 \%$ women in group 2 had complete abortion $(\mathrm{P}$ value $=1)$. At period of gestation 7 weeks, $90 \%$ of women in group 1 whereas $100 \%$ women in group 2 had complete abortion $(\mathrm{P}$ value $=1)$. At period of gestation between 4 to 7 weeks, the efficacy rates of the two dosage regimens are statistically similar ( $p$ value $>0.05$ ). On the other hand, at period of gestation 8 weeks, $74.07 \%$ of women in group 1 and $94.44 \%$ of women in group 2 had complete abortion. $\mathrm{P}$ value was 0.031 which is statistically significant meaning that $800 \mu \mathrm{g}$ sublingual Misoprostol was more efficacious in achieving complete abortion at this period of gestation of 8 weeks. Overall, $90 \%$ of women in group 1 and $95 \%$ of women in group 2 had complete abortion. $\mathrm{P}$ value being 
0.369 which is statistically insignificant meaning that both the dosages are equally effective statistically.

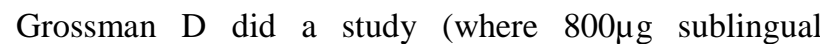
Misoprostol was used for the study), complete abortion was present in $98.2 \%$ women which is similar to present study. ${ }^{15}$ Similarly, in studies done by Tang OS et al, Hamoda et al and Helena et al complete abortion was present in $98.2 \%, 98.9 \%$ and $98.2 \%$ of women taking $800 \mu \mathrm{g}$ sublingual Misoprostol for first trimester abortion respectively. ${ }^{16,17,18}$ The occurrence of some side effects was significantly higher with $800 \mu \mathrm{g}$ Misoprostol as compared to $600 \mu \mathrm{g}$ Misoprostol. Nausea and vomiting was found to be significantly more in $800 \mu \mathrm{g}$ group as compared to $600 \mu \mathrm{g}(26.25 \%$ vs $5 \%$, p value $<0.0005)$ (Table 5). Nausea and vomiting was present in 4 out of 80 women (5\% women) in group 1 and 21 out of 80 women $(26.25 \%$ women) in group 2 . $\mathrm{P}$ value was $<0.005$ which is statistically significant. The side effects in terms of nausea and vomiting were significantly less with lower dosage (600ug) of Misoprostol as compared to $800 \mu \mathrm{g}$ sublingual Misoprostol.

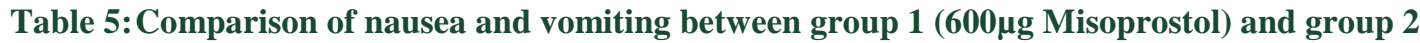

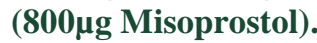

\begin{tabular}{|lllll|}
\hline & Groups & & Total & P value \\
\hline Nausea and vomiting & Group 1 & Group2 & & \\
\hline Total & $80(100.00 \%)$ & $21(26.25 \%)$ & $25(15.63 \%)$ & $<0.0005$ \\
\hline
\end{tabular}

According to study done by Jyothi et al, who used $800 \mu \mathrm{g}$ sublingual Misoprostol, where nausea and vomiting was present in 28 out of 58 women (48.3\%) taking sublingual Misoprostol. In a study done by Sadia Jalil et al where women were given $600 \mu \mathrm{g}$ sublingual Misoprostol, nausea was present in 3 out of $114(2 \%)$ women which was comparable to present study. ${ }^{12,19}$

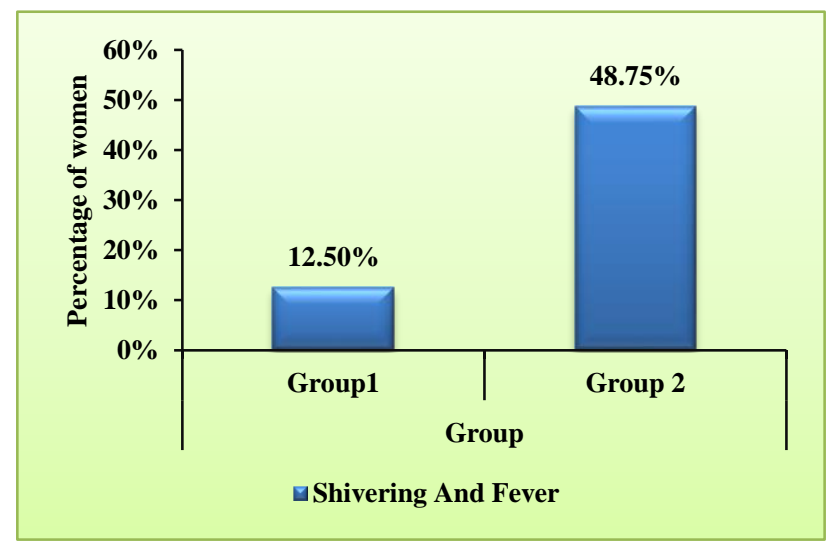

Figure 1: Comparison of shivering and fever in group $1(600 \mu \mathrm{g}$ Misoprostol) and group $2(800 \mu \mathrm{g}$ Misoprostol).

Vomiting was found to be statistically significant ( $\mathrm{p}$ value $=0.03$ ) in study done by Hamoda et al where women were given $800 \mu \mathrm{g}$ sublingual Misoprostol for first trimester abortion. ${ }^{17}$ Also, Kulier et al concluded that women taking $800 \mu \mathrm{g}$ sublingual Misoprostol had higher rates of nausea. ${ }^{20}$

Shivering was found to be significantly higher with higher dose of Misoprostol (48.75\% in $800 \mu \mathrm{g}$ group as compared to $12.50 \%$ in $600 \mu \mathrm{g}$ group, $\mathrm{p}$ value $<0.0005$ )
(Figure 1). Shivering and fever was present in 10 out 80 women (12.5\% women) belonging to group 1 and 39 out of 80 women $(48.75 \%$ women) belonging to group 2.P value was found to be less than 0.0005 which is statistically highly significant meaning shivering and fever was significantly less in women who took $600 \mu \mathrm{g}$ sublingual Misoprostol as compared to women taking $800 \mu \mathrm{g}$ sublingual Misoprostol. Similar results were found in study done by Oi Shan Tang where $38 \%$ of women taking $800 \mu \mathrm{g}$ sublingual Misoprostol suffered from shivering. ${ }^{21}$ Similarly, in a study done by Jyothi et al, who used $800 \mu \mathrm{g}$ sublingual Misoprostol for first trimester abortion, 30 out of $58(51.7 \%)$ women suffered from shivering. ${ }^{12} \mathrm{P}$ value was $<0.001$ which is highly statistically significant. Itching was found in 5\% of women in group 1 and $21.25 \%$ of women in group 2 which is again statistically highly significant ( $\mathrm{p}$ value was 0.004) (Figure 2).

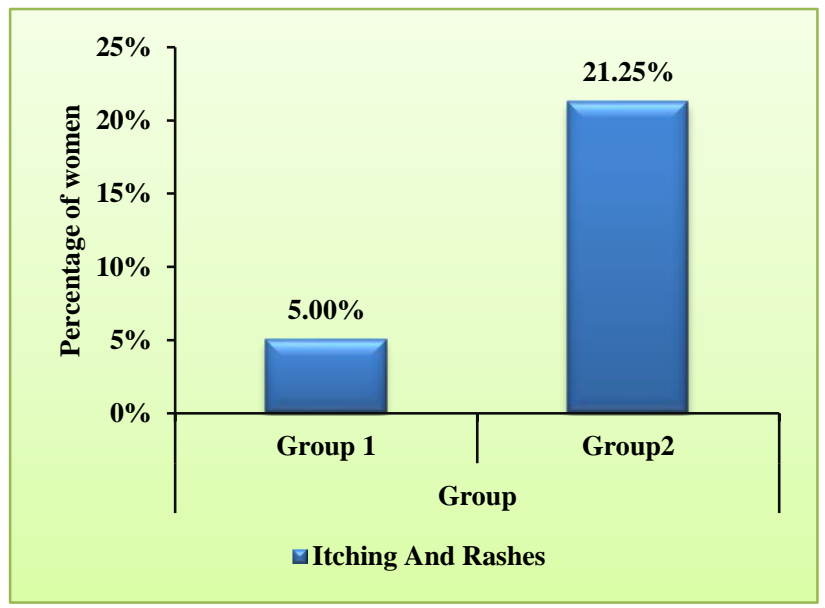

Figure 2: Comparison of itching and rashes in group 1 (600 $\mu \mathrm{g}$ Misoprostol) and group $2(800 \mu \mathrm{g}$ Misoprostol). 
Itching and rashes were present in 4 out 80 women $(5 \%$ women) belonging to group 1 and 17 out of 80 women (21.25\% women) belonging to group 2 .

$\mathrm{P}$ value was found out to be 0.004 which is statistically significant meaning that itching and rashes were significantly more in women taking $800 \mu \mathrm{g}$ Sublingual Misoprostol as compared to women taking $600 \mu \mathrm{g}$ Sublingual Misoprostol. The results in my study were comparable to study done by Kulier et al, who concluded that women receiving $800 \mu \mathrm{g}$ sublingual Misoprostol suffer from higher rates of itching and other side effects. ${ }^{20}$ Abdominal cramps was found in $10 \%$ women in women taking $600 \mu \mathrm{g}$ Misoprostol and $40 \%$ of women taking $800 \mu \mathrm{g}$ Misoprostol, which is statistically highly significant $(\mathrm{p}$ value $=0.001)($ Figure 3$)$.

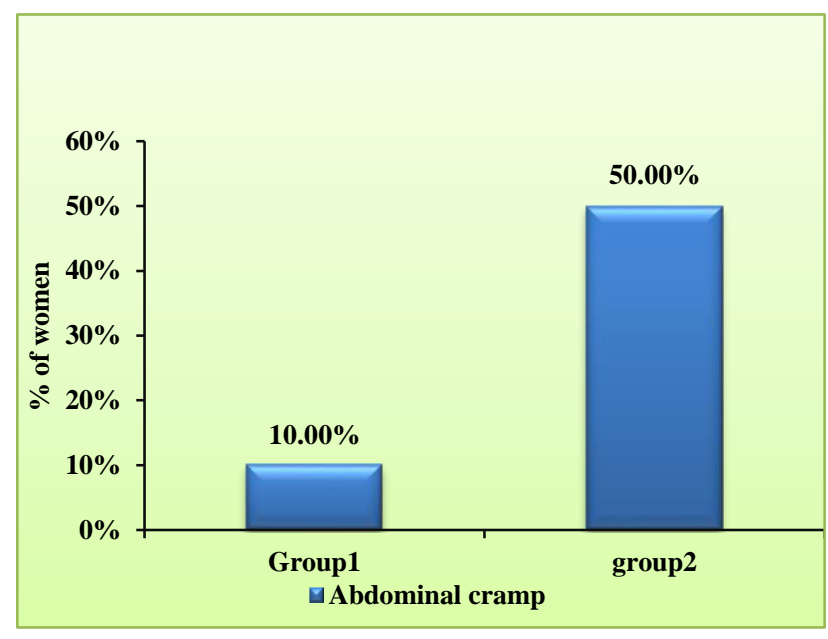

Figure 3: Comparison of abdominal cramps in group $1(600 \mu \mathrm{g}$ Misoprostol) and group 2

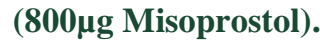

Abdominal cramps was present in 8 out 80 women $(10 \%$ women) belonging to group 1 and 40 out of 80 women (50\% women) belonging to group 2. $\mathrm{P}$ value was 0.001 which is highly statistically significant meaning thereby women taking $800 \mu \mathrm{g}$ sublingual Misoprostol suffered from more abdominal cramps.

The results in present study were consistent with study done by Oi Shan Tang, abdominal cramps was found to be present in $89 \%$ of women taking $800 \mu \mathrm{g}$ sublingual Misoprostol for termination of first trimester abortion. ${ }^{21}$

Diarrhoea was found to be more in women taking $800 \mu \mathrm{g}$ sublingual Misoprostol as compared to women who took $600 \mu \mathrm{g}$ sublingual Misoprostol who did not have diarrhoea at all $(2.5 \%$ vs $0 \%$, p value $=0.497)$, which is statistically comparable (Figure 4).

None of the women taking $600 \mu \mathrm{g}$ sublingual Misoprostol had diarrhoea (group1) whereas 2 out of 80 women $(2.5 \%$ women) belonging to group 2 suffered from diarrhoea. $\mathrm{P}$ value was 0.49 meaning thereby that the difference in the occurrence of diarrhoea was not statistically different in the two groups.

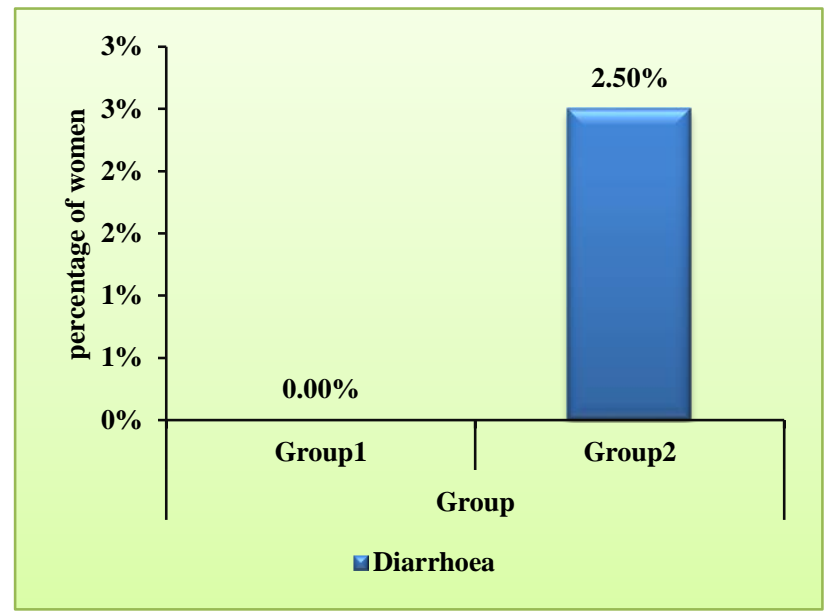

Figure 4: Comparison of diarrhoea in group $1(600 \mu \mathrm{g}$ Misoprostol) and group $2(800 \mu \mathrm{g}$ Misoprostol)

In study conducted by Jyothi et al (where $800 \mu \mathrm{g}$ sublingual Misoprostol was sued for the study), 22 out of $58(22 \%)$ women suffered from diarrhoea. $\mathrm{P}$ value was 0.005 which was highly statistically significant. ${ }^{12}$

Similarly Tang Os et al Kulier et al and Hamoda et al (p value $=0.02$ ), concluded that diarrhoea was significantly more in women taking $800 \mu \mathrm{g}$ sublingual Misoprostol for first trimester abortion. ${ }^{16,17,20}$

Similarly, in the study conducted by Oi Shan Tang et al, where $42 \%$ women suffered from diarrhoea who received $800 \mu \mathrm{g}$ sublingual Misoprostol. Drop in haemoglobin was statistically comparable in the two groups $(0.37 \%$ in group 1 vs $0.29 \%$ in group $2, \mathrm{P}$ value $=0.147)($ Figure 5$) .{ }^{21}$

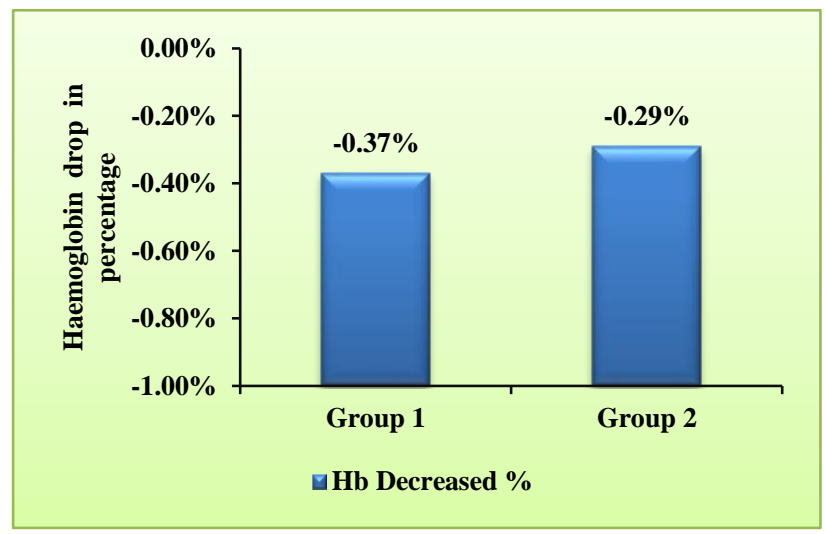

Figure 5: Comparison of haemoglobin drop in percentage between the two groups.

In terms of Haemoglobin drop in percentage, it was $0.37 \%$ in group 1 (sublingual $600 \mu \mathrm{g}$ Misoprostol) and $0.2 \%$ in group 2 (sublingual $800 \mu \mathrm{g}$ Misoprostol). P value 
was 0.147 which means haemoglobin drop in both the groups was statistically similar.

Jyothi et al, who used $800 \mu \mathrm{g}$ sublingual Misoprostol for the study, the bleeding lasted for 10.1 days. The mean haemoglobin on day 1 was $11.6 \mathrm{gm}$ and it was $11.5 \mathrm{gms}$ on day. ${ }^{12}$ In the study done by Sadia Jalil et al who used $600 \mu \mathrm{g}$ sublingual Misoprostol for their study, 6 out of $120(5 \%)$ women had heavy bleeding, 90 out of 120 (75\%) women had moderate bleeding and 24 out of 120 (20\%) women had mild bleeding. ${ }^{19}$

Oi Shan Tang used $800 \mu \mathrm{g}$ sublingual Misoprostol for first trimester abortion where median duration of bleeding was 17 days and 15 days respectively. More women taking $800 \mu \mathrm{g}$ sublingual Misoprostol needed analgesia as compared to $600 \mu \mathrm{g}$ Misoprostol (25\% vs $5 \%, \mathrm{P}$ value $=0.001$ ) which was statistically highly significant (Figure 6). ${ }^{21}$

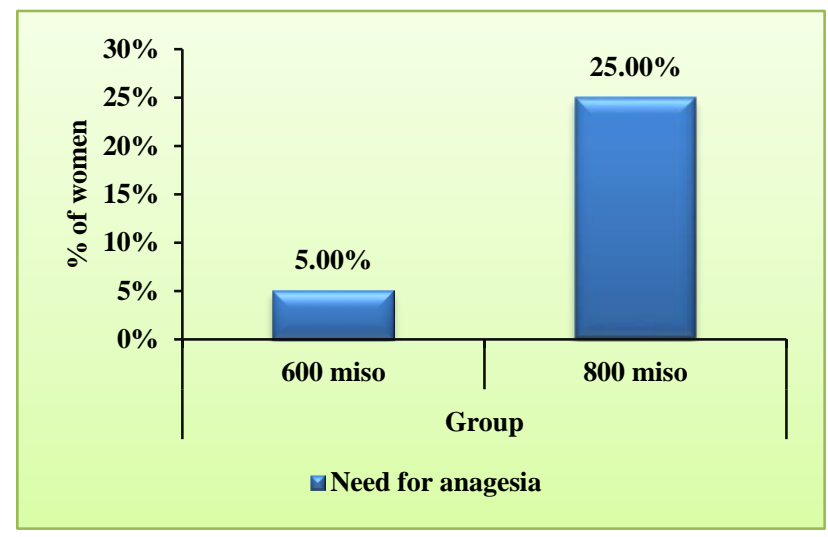

Figure 6: Comparison between the group1 and 2 in terms of need for analgesia

Analgesia was needed in 4 women out of 80 (5\% of women) in group 1 and 20 out of 80 women (25\% of women) in group 2. $\mathrm{P}$ value was 0.001 which is statistically significant. Hence need for analgesia was significantly more in women taking $800 \mu \mathrm{g}$ sublingual Misoprostol as compared to women taking $600 \mu \mathrm{g}$ sublingual Misoprostol. Results in my study were consistent with study done by Jyothi et al who used $800 \mu \mathrm{g}$ sublingual Misoprostol for their study, oral analgesics was needed for 12 out of $58(20 \%)$ women. ${ }^{12}$ Although more women taking $600 \mu \mathrm{g}$ sublingual Misoprostol needed additional dose of oxytocics as compared to women taking $800 \mu \mathrm{g}$ Misoprostol (10\% vs $3.75 \%$, p value $=0.210)$, but the difference was statistically insignificant (Figure 7).

Need of additional Oxytocics was in 8 women out of 80 (10\% women) belonging to group 1 and 3 out of 80 (3.75\% women) belonging to group 2 . P value was 0.210 meaning that although more women in group1 needed additional Oxytocics as compared to group 2, the difference was not statistically significant. The results are in contradiction to study done by Sadia et al (who used
$600 \mu \mathrm{g}$ sublingual Misoprostol for the study), where one dose of Misoprostol was needed in 20 out of $114(16 \%)$ women, two doses were needed in 96 out of $114(80 \%)$ women and three doses were needed in 4 out of 114 $(3.3 \%)$ women. ${ }^{19}$ Similar results were seen in studies done by Jyothi et al and Hamoda et al. ${ }^{12,17}$

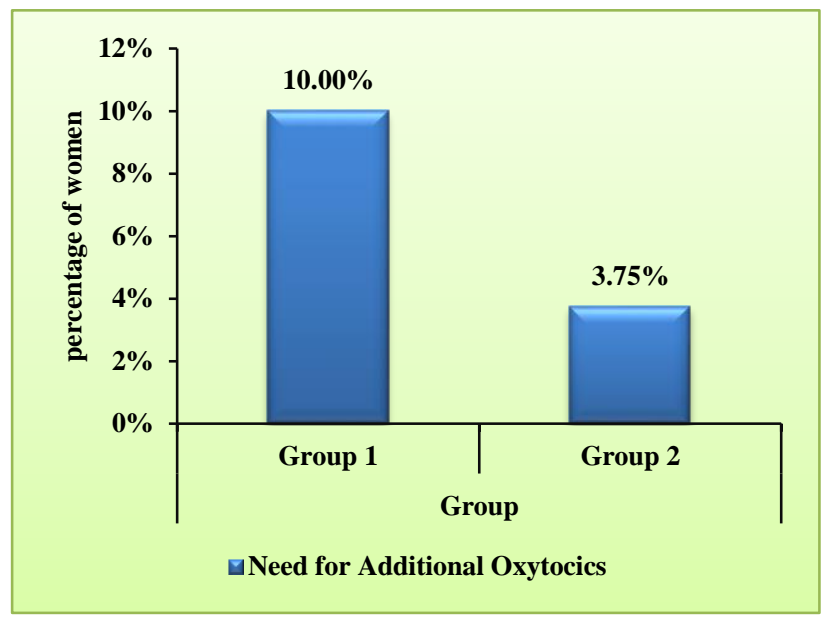

Figure 7: Comparison between group 1 and 2 in relation to need for additional oxytocics

\section{CONCLUSION}

Sublingual Misoprostol is comfortable and easier to administer when compared to other routes and it has potential to be developed as a self- administered regimen. $600 \mu \mathrm{g}$ sublingual Misoprostol is as efficacious as $800 \mu \mathrm{g}$ sublingual Misoprostol with significantly lesser side effects upto 7 weeks of period of gestation.

\section{Recommendations}

We recommend sublingual route for Misoprostol in termination of first trimester pregnancy as it is comfortable and easily accepted by women in comparison to vaginal route of Misoprostol. As per the present study, it is recommended to use of $600 \mu \mathrm{g}$ sublingual Misoprostol in period of gestation upto 7 weeks in women who want medical termination of pregnancy. Higher dose (800ug) of Misoprostol is recommended for termination of pregnancy more than 7 weeks up to 9 weeks period of gestation. However large Randomized Controlled Trials are required to compare different dosage regimens of sublingual Misoprostol to arrive at the minimum effective dose with minimum side effects and higher acceptability.

\section{ACKNOWLEDGMENTS}

Authors would like to thank Dr. Vikas Bedi, Dr. Rambhakta Thakur and Professor Dr. Usha Thakur for their support. Authors want to extend thanks to the patients and hospital for their cooperation.

Funding: No funding sources 
Conflict of interest: None declared

Ethical approval: The study was approved by the Institutional Ethics Committee

\section{REFERENCES}

1. WHO Reproductive Health Library commentary. Evidence summary. last revised:3 September 2004

2. Rodger MW, Baird DT. Induction of therapeutic abortion in early pregnancy with Mifepristone in combination with prostaglandin. Lancet. $1987 \mathrm{Dec}$ $19 ; 2(8573): 1415-8$.

3. RCOG.Care of Women Requesting Induced Abortion: Evidence-based clinical guideline number 7,2004 .

4. Bygdeman M, Swahn ML, Gemzell-Danielsson K, Svalander P. Mode of action of RU 486. Ann Med. 1993;25(1):61-4.

5. Spitz IM, Shoupe D, Sitruk- Ware R, Mishell DR Jr. Response to the antiprogestegen RU 486 (Mifepristone) during early pregnancy and the menstrual cycle in women.J Reprod Fertil Suppl. 1989;37:253-60.

6. Heikinheimo O, Ylikorkala O, Lahteenmaki P. Antiprogesterone $\mathrm{Ru}$ 486- a dr $\mu \mathrm{g}$ for non-surgical abortion. Ann Med. 1990;22(2):75-84.

7. Heikinheimo O. Antiprogesterone steroid RU 486. Pharmacokinetics and receptor binding in humans. Acta Obstet Gynecol Scand. 1990;69(4):357-8.

8. Tang OS, Schweer H, Seyberth HW, Lee SW, Ho PC. Pharmacokinetics of different routes of administration of misoprostol. Hum Reprod 2002; 17(2):332-6

9. Dahiya K, Mann S, Nanda S. Randomised trial of oral versus sublingual misoprostol 24 hour after mifepristone for medical abortion. Arch Gynaecol and Obstet. 2011;284(1):59-63.

10. AA S, VS R. Randomized Control Study of Oral Versus Vaginal and Sublingual Misoprostol with Mifepristone for First-Trimester MTP. Indian J Clinic Prac. 2013;24(7).

11. Shuchita M, Shveta K, Batya E, Suresh U. Simplifying medical abortion: home administration of misoprostol. J obstat Gynecol India. 2008;58(5):410-6.

12. Shetty J, Shanmugapriya T, Kamath A. Medical abortion by mifepristone with sublingual vs vaginal misoprostol: A randomised comparative trial. Health and Population: Perspect Iss. 2008;31(4):221-8.

13. Nusrat Shah. Sublingual versus vaginal misoprostol in the management of missed miscarriage.J Pak Med Assoc. 2010;60(2):113.

14. Mahler K. Early medical abortion regimens using different dosages of mifepristone are equally successful. Brit J Obstet Gynaecol. 2000;107(4):52430.

15. Grossman D. Evidence summary", Reproductive Health Library Commentary Evidence summary. WHO

16. Tang OS, Chan CC, Ng EH, Lee SW, Ho PC. A prospective, randomised, placebo-controlled trial on the use of Mifepristone with sublingual or vaginal misoprostol for medical abortions less than 9 week gestation. Hum Reprod. 2003;18(11):2315-8.

17. Hamoda H, Ashok PW, Pow J, Flett GM, Templeton A. A pilot study of mifepristone in combination with sublingual or vaginal misoprostol for medical termination of pregnancy up to 63 days gestation. Contracep. 2003;68(5):335-8.

18. Helena Von Hertzen et al," Comparision of two doses and the two routes of administration of Misoprostol after pretreatment with Mifepristone for early pregnancy termination", Reproduct Health 2008;5(1):2.

19. Jalil S. Sublingual Misoprostol in the management of first trimester miscarriage. Pak J Surg. 2010;26(2):169-73

20. Kulier R, Kapp N, Gülmezoglu AM, Hofmeyr GJ, Cheng L, Campana A. Medical methods for first trimester abortion. The Cochrane Library. 2011 Nov.

21. Tang OS, Xu J, Cheng L, Lee SWH, Ho PC. Pilot study on the use of sublingual misoprostol with mifepristone in termination of first trimester pregnancy up to 9 weeks gestation.Hum. Reprod.2002;17(7):1738-40.

Cite this article as: Thakur S, Pratap C. Comparison between sublingual 600 and 800 microgram misoprostol after mifepristone for MTP up to 9 weeks gestation. Int J Reprod Contracept Obstet Gynecol 2018;7:4996-5004. 